\title{
EFECTO DE RIZOBACTERIAS EN EL ENRAIZAMIENTO DE MINIESTACAS EN DOS CLONES HÍBRIDOS DE Eucalyptus spp.
}

\author{
González-Candia, Paulina; Rodríguez, Francisco; \\ Sanfuentes Eugenio ${ }^{6}$ y Sossa, Katherine.
}

\section{RESUMEN}

En la constante búsqueda de tecnologías que incrementen el enraizamiento en miniestacas de Eucalyptus spp, el uso de rizobacterias ha emergido como una alternativa viable. Las rizobacterias utilizan los exudados de la raíz de las plantas como fuente de carbono y nitrógeno y a su vez poseen diversos mecanismos que pueden promover el crecimiento de las plantas.

Este efecto de rizobacterias en el crecimiento y enraizamiento de plantas ha sido demostrado en varios cultivos agrícolas, pero aún son escasas las investigaciones en especies forestales. El objetivo del estudio fue evaluar el efecto de rizobacterias en el enraizamiento de miniestacas de dos clones híbridos de Eucalyptus (E. nitens $\times$ E. globulus).

Fueron aisladas 106 cepas bacterianas desde la rizósfera de cinco clones de Eucalyptus spp., usando los medios selectivos CCY, KB, AC y R2A. Posteriormente, se realizaron tres ensayos (E1, E2, E3) en vivero aplicando las cepas bacterianas al substrato $\left(10^{8} \mathrm{ufc} / \mathrm{ml}\right)$ y directamente en la base de las miniestacas. En cada ensayo se emplearon dos controles, consistentes en agua destilada estéril y caldo de cultivo estéril.

Los ensayos fueron realizados en el vivero Los Ángeles, localizado en la ciudad de Los Ángeles, de propiedad de Forestal Mininco S.A., entre enero y octubre de 2011 y enero del 2012, bajo condiciones operacionales de producción de plantas.

En el primer ensayo se utilizó un clon híbrido evaluándose las 106 cepas aisladas. En los dos ensayos siguientes se utilizaron 32 y 20 cepas aplicadas en dos clones híbridos, para E2 y E3, respectivamente, seleccionadas de acuerdo al resultado del ensayo precedente.

El diseño experimental fue de bloques completos al azar, empleándose 20 miniestacas por repetición para E1 y E2, y 30 miniestacas en E3. Después de 45 días del establecimiento de las miniestacas, en los tres ensayos se evaluó el enraizamiento (\%), además de la longitud de raíz (cm) y biomasa de raíz $(\mathrm{mg})$ en E2 y E3. Los resultados fueron analizados mediante test paramétricos o no paramétricos, en función de la distribución de los residuos (SAS 9.2).

En el primer ensayo 32 cepas bacterianas aumentaron significativamente el enraizamiento de las miniestacas, con una ganancia máxima de $47 \%$. En el segundo ensayo, 9 y 7 cepas tuvieron efecto significativo en el enraizamiento de ambos clones, con ganancias de 17 y $14 \%$, respectivamente. A su vez, 7 cepas incrementaron la longitud de raíz y 3 cepas coincidieron en promover el enraizamiento y la longitud de raíces en uno de los clones. En el tercer ensayo, 13 cepas aumentaron el enraizamiento, con ganancias entre 33 y $12 \%$ para ambos clones; coincidiendo 12 cepas en promover el enraizamiento en ambos clones.

Los resultados de esta investigación constataron que 12 cepas de rizobacterias promovieron simultáneamente el enraizamiento en ambos clones y 9 aumentaron la longitud de la raíz en al menos un clon; evidenciándose además una respuesta diferencial bacteria $\mathrm{x}$ clon.

Palabras clave: Eucalyptus, Enraizamiento, Rizobacterias.

\footnotetext{
${ }^{6}$ Facultad de Ciencias Forestales, Universidad de Concepción, Chile. esanfuen@udec.cl
} 


\section{SUMMARY}

Vegetative propagation techniques are an important tool in Eucalypts silviculture and improvement, within them microcuttings rooting is an important one and the rooting capacity rising is a continuous research objective. The use of rhyzobacterias to improve rooting capacity has emerged as viable alternative. That kind of bacterium uses plant root exudes as a carbon and nitrogen source and also has some mechanisms that can promote the plant growth. This effect has been demonstrated in several agriculture crops, but forest species research on the matter is still scarce. Main objective of this paper is to evaluate the rhyzobacterias effect on Eucalyptus spp hybrid clones microcuttings rooting.

A total of 106 bacterium strains were isolated from the roots of five Eucalypts clones by using the $C C Y, K B, A C$ y R2A selective means. Afterwards three trials (E1, E2, E3) were established at the nursery adding these strains to de substratum $\left(10^{8} \mathrm{ufc} / \mathrm{ml}\right)$ and directly to the micro cuttings bottom. Each trial includes two controls consisting in sterile distilled water and sterile culture media. Trials were carried out in the Forestal Mininco's Los Angeles nursery between January 2011 and January 2012 under operational plant production conditions.

The first trial included one hybrid clone and all 106 strains were evaluated. The other two trails included 30 and 32 strains in two hybrid clones, E2 and E3, respectively, selected accordingly to the results of the first trial. Experimental design was complete randomized blocks using 20 microcuttings by replication for $\mathrm{E} 1$ and $\mathrm{E} 2$, and 30 microcuttings for $\mathrm{E} 3$. After 45 days from the microcuttings establishment the rooting (\%) was evaluated in all trials as well as the root length $(\mathrm{cm})$ and the root biomass (mg) in E2 and E3. Results were analized through parametric or non parametric test in function of the residues distribution (SAS 9.2).

The first trail showed that 32 strains increased significantly the microcuttings rooting with a maximun gain up to $47 \%$. The second trial results on 9 and 7 strains showing a significantly effect on the rootting of both clones, with $17 \%$ and $14 \%$ gain, respectively. Also 7 strains increased root length and 3 strains increased root length and rooting in one of the clones. Regarding to the third trial, 13 strains increased the rooting with gains between $33 \%$ and $12 \%$ for the two clones and 12 of them increased the rooting in both clones.

Results of the research verify that 12 strains promoted simultaneously the rooting of the two clones and 9 strains increased the root length of at least one of the clones. A differentiating response bacterium $x$ clon strains was also verified.

Key words: Eucalyptus, Rooting, Rhyzobacterias. 


\section{INTRODUCCIÓN}

Eucalyptus globulus es la especie forestal más importante en Chile después de Pinus radiata, se la utiliza principalmente en la producción de celulosa para exportación, dado que posee fibra corta de buena calidad, alta densidad de madera y bajo contenido de lignina, características que favorecen la extracción de celulosa.

Además de identificar genotipos superiores que produzcan fenotipos más favorables, los programas de mejoramiento han sido dirigidos a la hibridación. Los fenotipos híbridos presentan características deseadas, tales como rápido crecimiento y tolerancia a diferentes causas de estrés. Así la hibridación intraespecífica en Eucalyptus es una alternativa de gran impacto y relativo bajo costo en programas de mejoramiento de árboles de interés (Assis, 2004, Poke et al., 2005).

Dentro de las estrategias de producción de Eucalyptus spp. en vivero, la reproducción asexual, definida como la reproducción de plantas empleando partes vegetativas de estas, ha generado una profusa línea de investigación fisiológica y de aplicación biotecnológica conducente a la propagación vegetativa de material vegetal genéticamente sobresaliente. La propagación vegetativa es bien conocida debido a las variadas ventajas que posee con respecto a la producción de plantas desde semillas, como son la uniformidad genética, su adaptación, menor costo y alta tasa de producción (Sotelo y Monza, 2007), lo que la convierte en una importante herramienta para aumentar la competitividad de la industria forestal.

Este sistema ha utilizado con éxito varios tipos de material vegetal, tales como estacas y miniestacas, producido desde plantas madres para la propagación de clones de Eucalyptus sp. (Sasse y Sands, 1995; Pardos, 2007). En los sistemas de propagación a gran escala el enraizamiento del material vegetal (estacas o miniestacas), es una etapa crucial en el éxito de este método de producción.

Sin embargo, existen inconvenientes, como el bajo enraizamiento en las estacas y las grandes variaciones en la capacidad de enraizamiento entre las especies y clones híbridos, observándose a menudo una reducción gradual en el potencial de enraizar (Penchel et al., 1995, Teixeira et al., 2007; Xavier et al., 1997; Schwambach et al., 2005).

Por lo tanto, a pesar de los avances en las técnicas de clonamiento y aumento en las tasas de enraizamiento, aún es posible observar importantes variaciones entre especies de Eucalyptus (Mafia et al., 2007a; Teixeira et al., 2007). Esta limitante en la técnica ha promovido el intenso estudio del enraizamiento adventicio en la propagación clonal de Eucalytus spp.

El enraizamiento es afectado por múltiples factores, tanto endógenos como exógenos. Los factores propios de la planta son la juvenilidad de los brotes, la posición de los brotes de los cuales las estacas son extraídas, el diámetro de las estacas, la presencia de yemas u hojas, el período de colecta de las estacas, la especie, el estado de dormancia y el nivel nutricional.

Existen asimismo aspectos bioquímicos asociados al enraizamiento, como fitohormonas, compuestos fenólicos y las características genéticas de la planta (Hand, 1994).

Existen también factores ambientales que pueden afectar el enraizamiento, como la humedad, la luminosidad, el fotoperíodo, la composición química del substrato, la temperatura, el estrés y los microorganismos presentes en el suelo (Higashi et al., 2000).

En el enraizamiento adventicio se reorganizan células del floema secundario, del cambium o de los radios parenquimáticos, que al desarrollarse se transforman en primordios radiculares. En condiciones adecuadas estos primordios crecen, atraviesan la corteza y emergen al exterior mientras que en el interior se conectan con el sistema conductor (floema y xilema).

La diferenciación y emisión de los primordios radiculares puede venir acompañada de la formación de un tejido parenquimático de cicatriz denominado callo en la base de las estacas, el cual impide el acceso de patógenos al interior de las estacas sin influenciar la rizogénesis (Baldini, 1992). 
El enraizamiento adventicio consta de tres fases sucesivas: a) Inducción, donde ocurren principalmente eventos moleculares y bioquímicos, b) Iniciación, divisiones celulares con la formación de los meristemas de la raíz, y c) Expresión, consistente en la aparición de la raíz (Kevers et al., 1997).

En la constante búsqueda de metodologías que mejoren el enraizamiento del material de propagación en especies de interés comercial, el uso de rizobacterias promotoras del crecimiento en plantas, en adelante PGPR, ha emergido como una estrategia promisoria en vista de las posibilidades de aumentar el enraizamiento, el crecimiento y el control biológico.

La capacidad de mejorar el crecimiento y rendimiento de plantas por parte de este tipo de bacterias ha sido demostrada mayormente en cultivos agrícolas (Erturk et al., 2009) y también en algunas especies forestales (Chanway, 1997; Karthikeyan y Sakthivel, 2011). Estas bacterias habitan principalmente la rizósfera, aunque también pueden encontrarse en el rizoplano y dentro de las plantas, en cuyo caso se denominan bacterias endófitas (Gray y Smith, 2005).

La rizósfera es aquella zona del suelo que está directamente influenciada por las raíces, afectando sus exudados los procesos físicos, químicos y biológicos del suelo. Las raíces de las plantas exudan una amplia gama de compuestos de pequeño y gran peso molecular, incluyendo iones, agua, enzimas, mucílagos, aminoácidos, ácidos orgánicos, proteínas, azúcares y compuestos fenólicos (Bais et al., 2006).

La interacción que se da entre las raíces de plantas y las bacterias se debe a la utilización por parte de las bacterias de los exudados de las plantas como fuente de carbono y nitrógeno (Benizri et al., 2001). Estas pueden influenciar positivamente el crecimiento de la planta a través de mecanismos directos e indirectos que incluyen la fijación de nitrógeno atmosférico y aumento de la tolerancia a estrés biótico-abiótico.

Los mecanismos indirectos de las PGPR hacia las plantas radican principalmente en su efecto contra fitopatógenos, siendo mediado por competencia por espacio y nutrientes, producción de antibióticos y sideróforos, inducción de resistencia sistémica y parasitismo (Ping \& Boland 2004; Romeiro et al., 2005; Siddiqui, 2006; Compant et al., 2010).

A su vez, los mecanismos directos describen la estimulación del crecimiento de la planta mediante la facilitación de compuestos nutritivos, ya sea produciéndolos o facilitando su captación. Ejemplo de esto es la fijación de nitrógeno atmosférico, la síntesis de distintas fitohormonas, la solubilización de minerales y la síntesis de enzimas que pueden modular los niveles de fitohormonas en las plantas (Penrose y Glick, 2003; Siddiqui, 2006).

Sustentado en la capacidad de promover el crecimiento de las plantas es que a las PGPR se les ha atribuido la cualidad de "Biofertilizante". La definición de este concepto fue acuñada por Vessey (2003) quien la describió como "una sustancia que contiene microorganismos vivos, y que al aplicarse a semillas, superficie de plantas o suelo, colonizan la rizósfera o el interior de la planta promoviendo el crecimiento de esta al aumentar el suministro o la capacidad de captar nutrientes".

La utilización de biofertilizantes posee como mayor cualidad disminuir el impacto ambiental negativo resultante del continuo uso de fertilizantes químicos (Adesemoye et al., 2009). Dentro de los principales géneros a los cuales pertenecen este tipos de bacteria se encuentran Bacillus, Azospirillum, Pseudomonas, Enterobacter, Paenibacillus, entre otros (Chanway, 1997; Bent et al., 2002; Bais et al., 2006, Compant et al., 2010; Eneback, 2005; Erturk et al., 2010).

El efecto de las rizobacterias en el crecimiento de plantas de especies forestales ha sido demostrado. Chanway (1997) da cuenta de los efectos de inóculos bacterianos en el crecimiento de Pinus contorta, donde la inoculación de plantas de cuatro meses con la cepa Bacillus polymyxa L6-16R incrementó la biomasa de estas en cerca de un 33\%.

En cuanto al enraizamiento, se han descrito efectos significativos en miniestacas de 3 
clones de Eucalyptus spp. presentando incrementos tanto en la frecuencia de enraizamiento, como en la biomasa, luego de la inoculación con cepas bacterianas aisladas desde rizoplano y rizósfera (Teixeira et al., 2007).

La influencia de las rizobacterias también ha sido comprobada en diferentes condiciones de propagación clonal, variando los resultados de acuerdo al clon de Eucalyptus y el aislado rizobacterial evaluado, obteniéndose para las mejores cepas estudiadas incrementos de $21,4 \%$ y $78,0 \%$ para enraizamiento y biomasa de raíces, respectivamente (Mafia et al., 2007a).

La acción de las rizobacterias ha sido también evaluada en estacas de varias especies de Eucalyptus, tales como E. globulus, donde se observaron aumentos de $47 \%$ en el porcentaje de enraizamiento en estacas inoculadas con cepas aisladas de la rizósfera de E. globulus (Díaz et al., 2009), y en E. camaldulensis donde la inoculación con Azotobacter chroococum mostró aumentos significativos en la biomasa, numero de raíces, longitud de raíz y porcentaje de enraizamiento (Karthikeyan y Sakthivel, 2011).

Los antecedentes descritos anteriormente dan cuenta de la capacidad y potencial del uso de rizobacterias como biofertilizante para estimular el crecimiento y enraizamiento de Eucalyptus spp. en estados tempranos de su producción (estacas y miniestacas), beneficiando el posterior establecimiento de este.

\section{OBJETIVO}

Evaluar el efecto de rizobacterias aisladas desde la rizósfera de varios clones de Eucalyptus spp. en el enraizamiento de miniestacas de dos clones híbridos recalcitrantes ( $E$. nitens $x$ E. globulus).

\section{MATERIAL Y MÉTODO}

\section{Localización de los Ensayos}

Los ensayos fueron realizados en el vivero de la empresa Forestal Mininco SA ubicado en la ciudad de Los Ángeles, región del Bio Bio. Se realizaron tres ensayos, de 45 días cada uno en las siguientes fechas: Enero 2011 (E1), Octubre 2011 (E2) y Enero 2012 (E3).

\section{Material Vegetal Utilizado}

Fueron utilizados los clones de E. nitens x E. globulus X-64 y X-65.

En los ensayos E1 y E2 se utilizaron miniestacas de segundo orden, las cuales contaban con dos hojas.

Para el ensayo E3 se usaron miniestacas apicales que contaban con dos a tres pares de hojas, obtenidas desde los ápices de las plantas madres.

\section{Cepas Bacterianas y Formas de Aplicación}

Las cepas fueron aisladas desde la rizósfera de cinco clones de Eucalyptus spp.; $E$. globulus X-49 y X-52, E. nitens x E. globulus X-64 y X-65, y E. globulus x E. camaldulensis X-89. Las rizobacterias se aislaron en medios selectivos: CCY para Bacillus spp., KB para Pseudomonas spp, AC para Streptomyces spp y R2A como medio general.

Luego de sembrar las muestras de rizósfera diluidas, se obtuvieron distintas colonias, las cuales fueron caracterizadas por color, forma, tamaño, relieve y opacidad. Se aislaron 106 cepas las que fueron almacenadas a $-80^{\circ} \mathrm{C}$.

La inoculación de las rizobacterias en el substrato se realizó de la misma forma en los 
tres ensayos, mientras que las modificaciones solo se remitieron a cambios proporcionales en las cantidades de inoculo y volumen de substrato utilizado. Una vez reactivadas las cepas bacterianas en medio nutritivo sólido (agar R2A - $48 \mathrm{hrs}-25^{\circ} \mathrm{C}$ ), estas fueron cultivadas en medio nutritivo líquido (caldo R2A - $48 \mathrm{~h}-25^{\circ} \mathrm{C}-120 \mathrm{RPM}$ ), alcanzando una concentración de $1 \times 10^{8} \mathrm{UFC} / \mathrm{ml}$, en el volumen final.

Además de los tratamientos con rizobacterias, se incluyeron dos controles; agua destilada (Control A) y caldo de cultivo R2A estéril (Control C). La suspensión bacteriana (120 ml), fue inoculada en el substrato mediante aspersión incubándose este a $25^{\circ} \mathrm{C}$ por $48 \mathrm{~h}$, antes de montar cada ensayo. El substrato consintió en una mezcla de turba, vermiculita y perlita (50-30$20 \%$, respectivamente). El substrato fue inoculado por separado con cada tratamiento (cepa de rizobacteria).

Adicionalmente, en vivero las bases de las miniestacas fueron inoculadas con cada cepa bacteriana (tratamiento) mediante inmersión de la zona de corte, por aproximadamente 20 segundos, e inmediatamente colocadas en sus respectivos recipientes que contenían el substrato previamente inoculado con la misma rizobacteria.

\section{Diseño de los Ensayos}

- Ensayo 1 (E1): Bloques Completos al Azar, tres bloques, clon E. nitens x E. globulus X-64, 106 tratamientos y 1 control (agua). Unidad experimental 20 estacas.

- Ensayo 2 (E2): Bloques Completos al Azar, cuatro bloques, dos clones de E. nitens x E. globulus (X-64 y X-65). Cada bloque contuvo 32 tratamientos y dos controles (caldo estéril sin bacterias y agua destilada). Unidad experimental 20 estacas (dos repeticiones dentro de cada bloque, 10 estacas cada una).

-Ensayo 3 (E3): Bloques Completos al Azar, cuatro bloques, dos clones de E. nitens $\times$ E. globulus (X-64 y X-65). Cada bloque contenía 20 tratamientos y dos controles (caldo estéril sin bacterias y agua destilada). Unidad experimental 30 estacas (dos repeticiones dentro de cada bloque, 15 estacas cada una).

En los ensayos no se utilizaron hormonas, se mantuvo una humedad relativa del $80 \%$ y temperatura de $25^{\circ} \mathrm{C}$. En E2 y E3 se utilizó el fungicida Pomarsol a $800 \mathrm{ppm}$.

\section{Evaluación de los Ensayos}

Trascurridos 45 días del montaje de ensayo se procedió a evaluar las miniestacas. Las variables evaluadas fueron: Miniestacas enraizadas por tratamiento ( $E 1)$, longitud de raíz y biomasa (E2 y E3). Otras variables como miniestacas con callo sin raíz, miniestacas muertas y miniestacas sin raíz ni callo, fueron registradas pero no evaluadas estadísticamente.

\section{Análisis Estadísticos}

Se analizó el porcentaje promedio de miniestacas enraizadas por tratamiento. También se evaluó longitud de raíz $(\mathrm{cm})$ y biomasa de la raíz expresada como peso seco en miligramos. Los resultados fueron analizados mediante test paramétricos o no paramétricos, en función de la distribución de los residuos (SAS 9.2).

\section{RESULTADOS}

\section{Ensayo 1}

El tratamiento control tuvo un porcentaje promedio de miniestacas enraizadas de $28 \%$. En la Figura $\mathrm{N}^{\circ} 1$ se muestra los 32 tratamientos en los que el porcentaje de enraizamiento fue significativamente mayor $(p>0,05)$ al control. La mayor ganancia para este ensayo fue de $47 \%$ y se obtuvo con el tratamiento 53. 


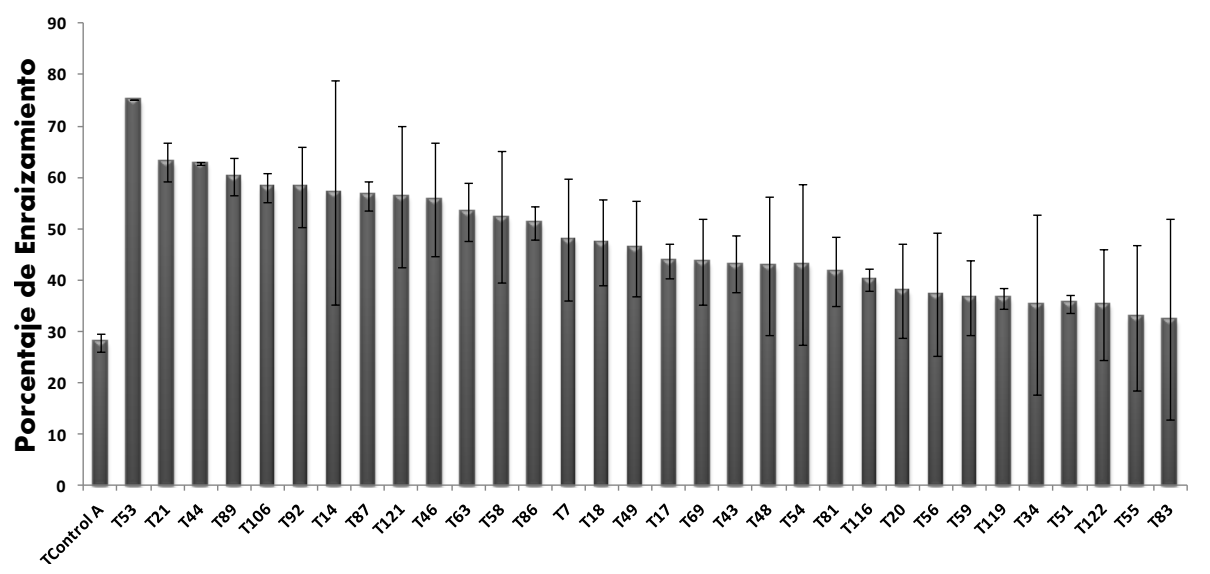

Se indican en orden descendente los tratamientos que aumentaron significativamente $(p>0,05)$ el porcentaje de enraizamiento respecto al control A. Se muestran promedios \pm error estándar.

Figura $\mathrm{N}^{\circ} 1$

PORCENTAJE DE ENRAIZAMIENTO PARA EL CLON X-64 POR TRATAMIENTO

\section{Ensayo 2}

\section{- Porcentaje de Enraizamiento}

En la Figura $\mathrm{N}^{\circ} 2$ se muestra el porcentaje de miniestacas enraizadas en E2 en los clones X-64 y X-65. En el clon X-64 los tratamientos control (Control A y Control C) mostraron un porcentaje promedio de miniestacas enraizadas de 1 y $5 \%$, respectivamente, y los mayores porcentajes oscilaron entre 9 y 18\% para esta variable. En el clon X-65 los tratamientos control mostraron un porcentaje promedio de miniestacas enraizadas de 26 y $29 \%$, respectivamente, además siete tratamientos aumentaron el enraizamiento con ganancias entre 41 y $39 \%$.

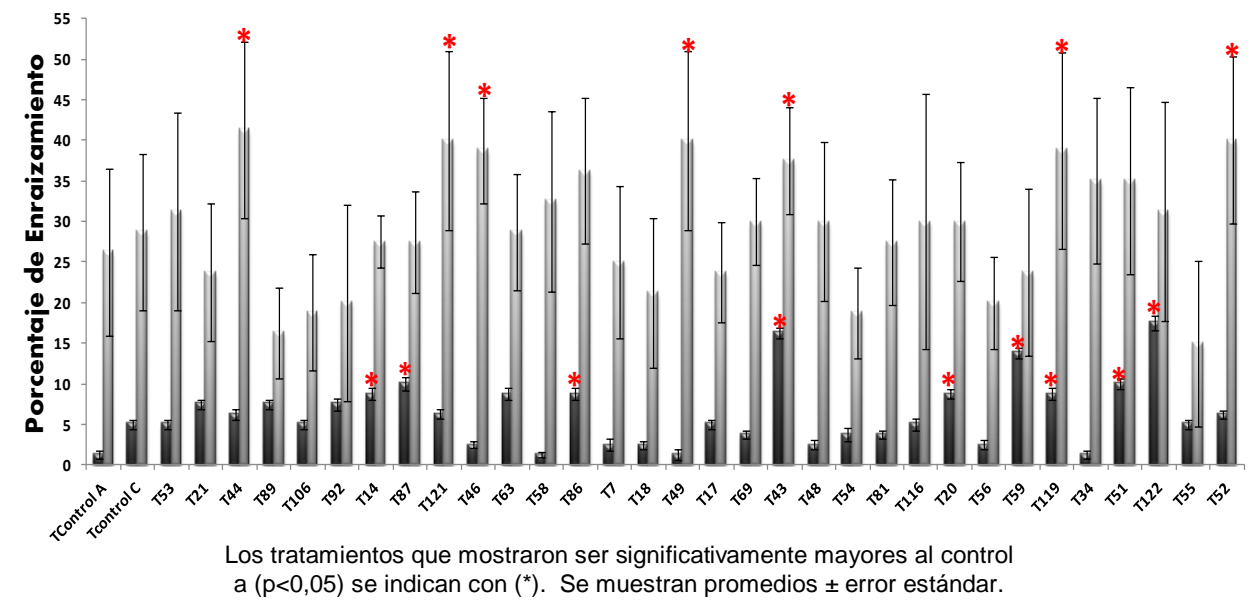

Figura $\mathrm{N}^{\circ} 2$

PORCENTAJES DE ENRAIZAMIENTO EN E2 POR TRATAMIENTO EL CLON X-64 (BARRAS OSCURAS) Y CLON X-65 (BARRAS CLARAS) 


\section{- $\quad$ Longitud de Raíces}

En la Figura $\mathrm{N}^{\circ} 3$ se muestran las longitudes de raíz en E2 para los clones X-64 y X-65. En el clon X-64 los tratamientos control (Control A y Control C) mostraron una longitud de 0,1 y 1 $\mathrm{cm}$, respectivamente.

Las mayores longitudes se obtuvieron con los tratamientos $89,69,122,44,43,59$ y 21 , siendo significativamente mayores $(p<0,05)$ al Control $A$. respectivamente.

En el clon X-65, los tratamientos control mostraron una longitud promedio 3,1 y $4,3 \mathrm{~cm}$,

En este caso no hubo diferencias significativamente entre los tratamientos y el control.

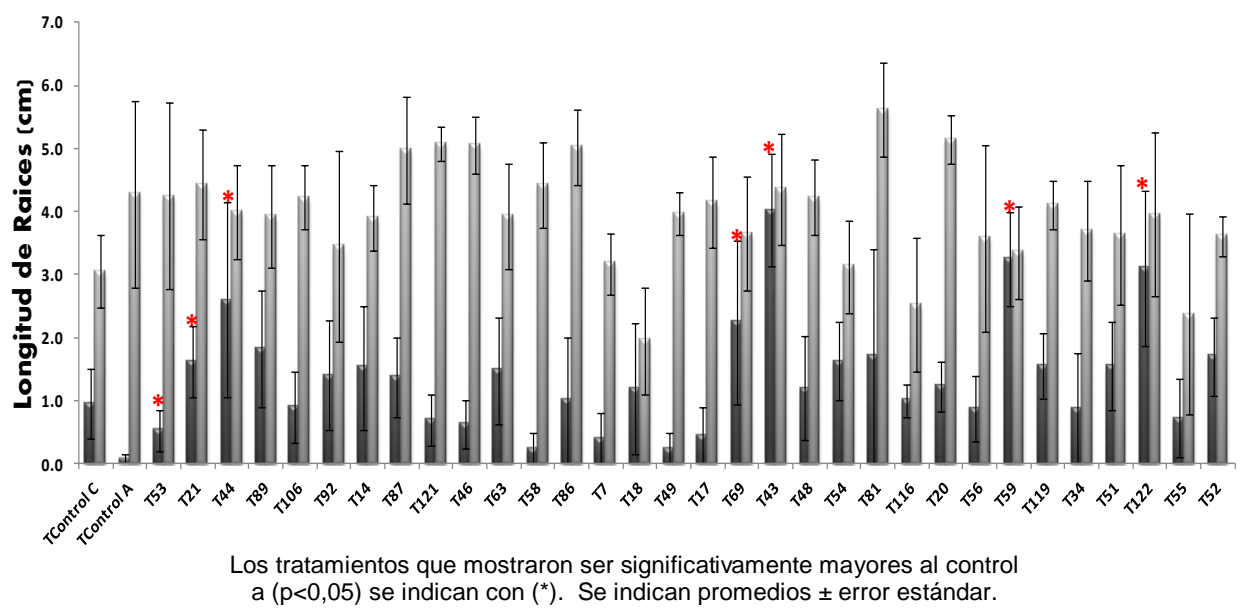

Figura $\mathbf{N}^{\circ} 3$

LONGITUD DE RAÍCES EN MINIESTACAS POR TRATAMIENTO CLON X-64 (BARRAS OSCURAS) Y CLON X-65 (BARRAS CLARAS)

\section{Ensayo 3} $\mathrm{X}-65$ en $\mathrm{E} 3$.

\section{Porcentaje de Enraizamiento}

En la Figura $N^{\circ} 4$ se muestra el porcentaje de miniestacas enraizadas para el clon X-64 y

En el clon X-64 los tratamientos control (Control A y Control C) mostraron un porcentaje promedio de miniestacas enraizadas de 7 y $18 \%$ respectivamente, y trece tratamientos fueron significativamente mayores a los controles.

Para el clon X-65, los tratamientos control mostraron un porcentaje promedio de miniestacas enraizadas de $54 \%$ y $76 \%$, además trece tratamientos en este clon fueron significativamente mayores al Control A. 


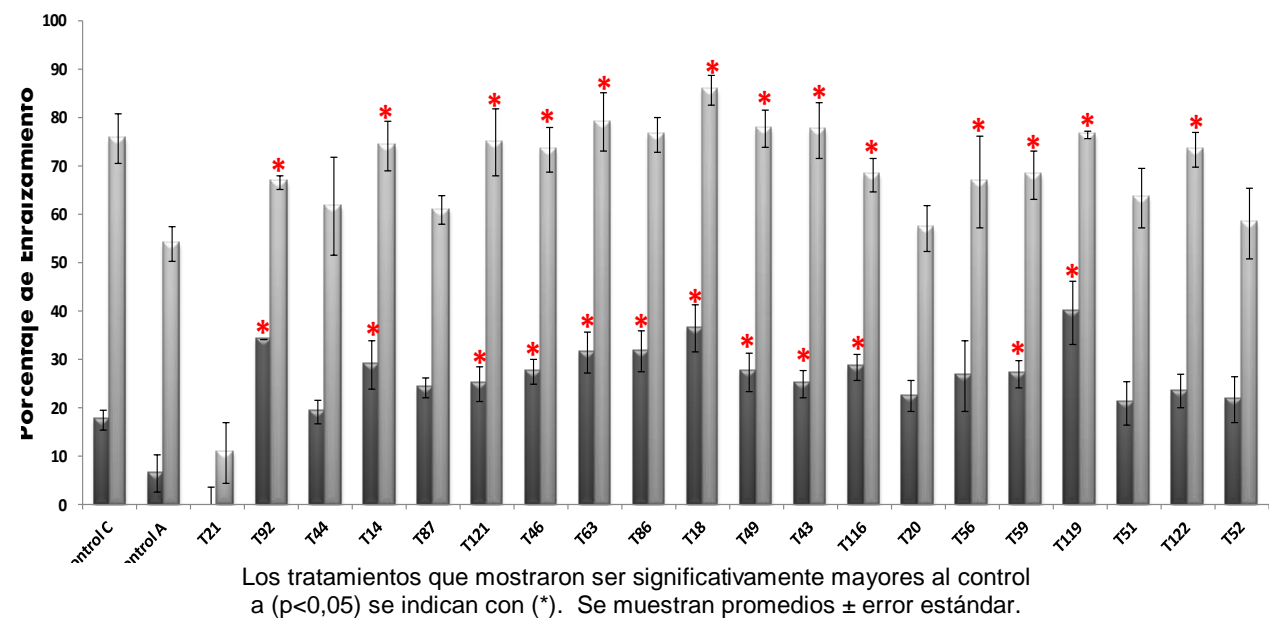

Figura $\mathrm{N}^{\circ} 4$

PORCENTAJES DE ENRAIZAMIENTO DE MINIESTACAS EN E3 POR TRATAMIENTO

CLON X-64 (BARRAS OSCURAS) Y CLON X-65 (BARRAS CLARAS)

\section{- $\quad$ Longitud de Raíces}

En la Figura $\mathrm{N}^{\circ} 5$ se muestran las longitudes de raíz en E3 para los clones X-64 y X-65. Las mayores longitudes se obtuvieron con los tratamientos 116, 14, 49, 52 y 56 . Sin embargo, no fueron significativamente mayores $(p<0,05)$ al control. En el clon $X-65$ las mayores longitudes se obtuvieron con los tratamientos $21,92,122$ y 14 . Sin embargo, no fueron significativamente mayores $(p<0,05)$ al Control $A$.

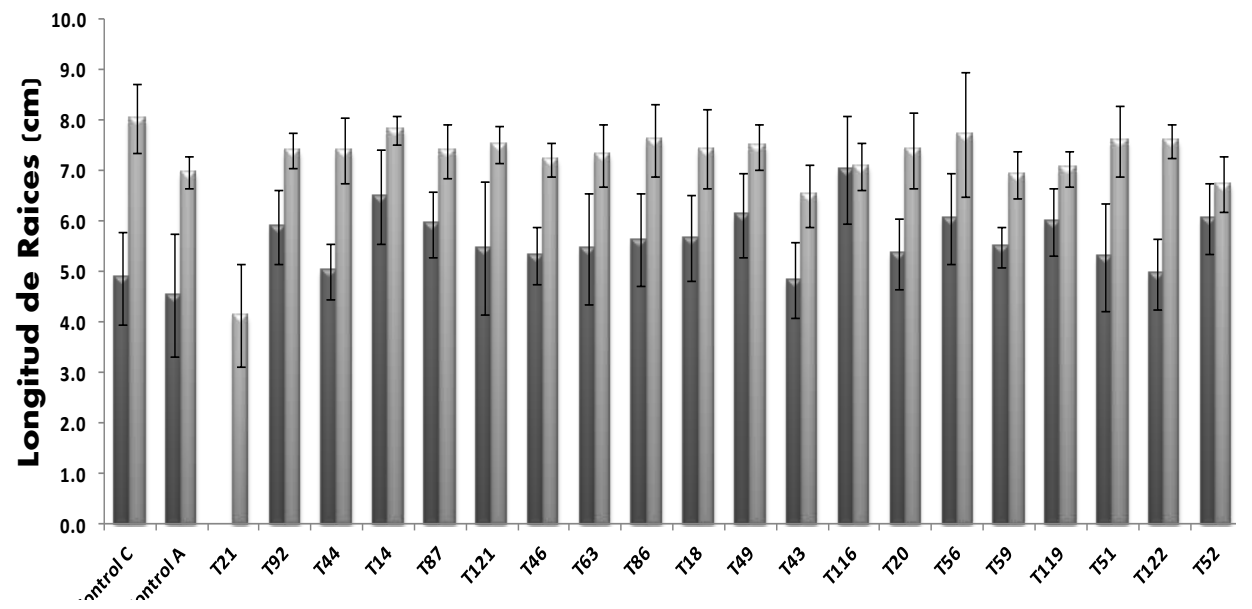

Se muestran promedios \pm error estándar.

Figura $\mathbf{N}^{\circ} 5$

LONGITUD DE RAÍCES EN MINIESTACAS POR TRATAMIENTO

CLON X-64 (BARRAS OSCURAS) Y EL CLON X-65 (BARRAS CLARAS) 


\section{DISCUSIÓN}

Hace varias décadas las bacterias han sido introducidas en el suelo para mejorar el crecimiento de plantas (Kloepper et al., 1989; Vessey, 2003; Bhattacharyya y Jha, 2012). La investigación acerca de su efecto en plantas y en semillas se ha centrado principalmente en mejorar cultivos agrícolas, más que en plantaciones forestales (Probanza et al., 2002).

Sin embargo, estudios sobre su efecto en el crecimiento y rendimiento de especies de interés forestal ha alcanzado relevancia (Chanway, 1997), en vista de la importancia de esta industria en países como Brasil, India y Chile (Pardos, 2007; Ferreira et al., 2008; Karthikeyan y Sakthivel, 2011).

El efecto de inoculantes bacterianos en el crecimiento se ha evaluado en coníferas como Pinus, Tsuga y Pseudotsuga (Chanway, 1997) y en la especie latifoliada Eucalyptus sp (Teixeira et al., 2007; Mafia et al., 2009; Puente et al., 2010). El interés por estos inoculantes bacterianos nace de la creciente necesidad de mejorar las etapas tempranas de producción de plantas, utilizando técnicas alternativas más amigables con el medio ambiente y menos costosas (Adesemoye et al., 2009). Así una de las mayores etapas limitantes en la producción clonal de Eucalyptus es el enraizamiento, donde se han observado dificultades debido a la disminución en la capacidad de enraizar y la variabilidad que se da en este rasgo entre clones de la misma especie.

En cuanto a los resultados obtenidos de este estudio compuesto de tres ensayos (E1, E2 y E3), se lograron aislar más de cien cepas rizobacterianas presentando las colonias una amplia variabilidad morfológica, esto en cuanto a su textura, color, forma, tamaño, opacidad y velocidad de crecimiento. La selección de los mejores aislados se hizo en base a los mayores porcentajes de enraizamiento y longitud de raíz, tomando en cuenta también la congruencia y/o frecuencia de estos aislados en los tres ensayos realizados.

En el primer ensayo (E1) de las 106 cepas evaluadas, 32 mostraron aumentar significativamente el porcentaje de enraizamiento en relación al tratamiento control en miniestacas del clon X-64. El control agua (A) fue utilizado para los análisis estadísticos descartándose el control caldo sin bacterias (C), ya que este último tuvo un efecto mayor que el del agua sin bacterias en el enraizamiento. Esto pudo deberse a la composición del caldo ya que sus nutrientes pudieron estimular el crecimiento de las bacterias nativas en el substrato repercutiendo esto en mayores valores de enraizamiento. En relación a esto, se ha observado un efecto en las rizobacterias al aplicar leche en polvo en el substrato, al constatarse un aumento en las variables porcentaje de enraizamiento y biomasa radicular debido a la utilización de la leche como fuente de nutrientes por parte de las rizobacterias (Mafia et al., 2007b). Asimismo, en el primer ensayo (E1) se observó una ganancia máxima en el porcentaje de enraizamiento de $47 \%$ en el tratamiento con mejor rendimiento (cepa 53).

Estos resultados implican mejores rendimientos a los obtenidos por Teixeira et al. (2007) en ensayos con estacas de un clon híbrido comercial de $E$. grandis, donde las bacterias lograron ganancias en el enraizamiento de aproximadamente $20 \%$.

En el segundo ensayo (E2), las 32 bacterias que tuvieron los mejores resultados de enraizamiento en E1, fueron ensayadas en los clones X-64 y X-65. Además, se evaluaron las variables de longitud promedio de la raíz y biomasa radicular. En este caso la respuesta fue variable en cuanto a los clones utilizados, siendo el clon X-65 el que respondió mejor en todas las variables evaluadas. En E2, de los 32 tratamientos evaluados, 9 y 7 tratamientos tuvieron efecto en el porcentaje de enraizamiento para los clones X-64 y X-65, respectivamente, con ganancias de 17 y $14 \%$. Para la variable longitud promedio de raíces, 7 tratamientos mostraron aumentar de manera significativa $(p>0,05)$ esta variable con respecto al control $(0,1 \mathrm{~cm})$ para el clon X-64.

Estos resultados son semejantes a los constatados por Karthikeyan y Sakthivel (2011), quienes obtuvieron aumentos significativos en la longitud de la raíz en estacas de E. camaldulensis inoculadas con Azotobacter chroococum. Los tratamientos 122, 43 y 59 son coincidentes en cuanto a favorecer al mismo tiempo las variables porcentaje de enraizamiento y longitud promedio de raíces en el clon X-64. Las demás variables para el clon X-65 y X-64, es decir, longitud promedio 
de raíz y biomasa radicular, no presentaron diferencias significativas en relación con sus respectivos controles. Además, se evaluó el control positivo hormona IBA (ácido-indol butírico) en E2, donde los tratamientos y el control negativo agua (A) no mostraron diferencias (datos no mostrados).

En E3 se evaluaron 20 tratamientos, los controles mostraron porcentajes de enraizamiento de 7 y $54 \%$ para los clones X-64 y X-65, respectivamente. En el primer clon 13 tratamientos mostraron aumentar significativamente $(p>0,05)$ el porcentaje de enraizamiento respecto a su control $(\mathrm{A})$ con ganancias entre 33 y $18 \%$. Para el clon $\mathrm{X}-65,13$ tratamientos fueron asimismo mayores al control $(p>0,05)$, con ganancias entre $32 \%$ y $12 \%$.

La magnitud de estos resultados es semejante a lo obtenido por Mafia et al. (2007a), que evaluó el efecto de Pseudomonas sp, Bacillus sp y Stenotrophomonas maltophilia en plantas de Eucalyptus en diferentes condiciones de propagación clonal. En dicho estudio se obtuvieron ganancias en el enraizamiento de $38 \%$.

El porcentaje de enraizamiento es una variable importante y frecuente a la hora de seleccionar cepas rizobacterianas como potenciales PGPR. Ejemplo de esto es los realizado por Díaz et al. (2009) quienes describieron e identificaron varias rizobacterias con efecto en el enraizamiento y ganancias del orden de $41 \%$, destacando las especies Bacillus subtilis/amyloliquefaciens y $B$. mycoides, que presentaron un mayor efecto en el enraizamiento de estacas de E. globulus clon X-53.

Un aspecto relevante en E3 es el tipo de material vegetal utilizado. Las miniestacas apicales, mostraron una mayor respuesta en el enraizamiento, esto principalmente por la influencia del ápice como fuente de fitohormonas, además al poseer este nuevo material más hojas (3 pares) también aumento la cantidad de fotosintatos disponibles para la planta (Taiz, 2007).

En el último ensayo (E3) se observó coincidencia en 12 de los 14 tratamientos con efecto en el enraizamiento en ambos clones, a excepción de las cepas 121, 122 y 86 que mostraron efecto en solo uno de los clones. La bacterias no incrementaron la longitud de raíces en ninguno de los clones, resultado que ha sido documentado previamente en estudios con plantas de Pinus taeda y P. pinea (Eneback, 2005; Probanza et al., 2002); aunque fue incrementado el crecimiento de las plantas. La biomasa de la raíz no fue afectada por las bacterias, contrastando con los resultados de otras investigaciones que dan cuenta del aumento en esta variables en raíces de plantas o estacas de varias especies forestales tratadas con diferentes cepas de rizobacterias (Mafia et al., 2005; Díaz et al., 2009; Erturk et al., 2010; Karthikeyan y Sakthivel, 2011). Sin embargo, los resultados son coincidentes con aquellos obtenidos por Probanza et al. (2002), en donde no siempre se logró un incremento en biomasa por parte de las bacterias.

En este estudio no se observó una tendencia marcada en cuanto al efecto de las rizobacterias y el clon del cual se aislaron. No obstante, se puede indicar que la mayoría de los aislados con efecto en el enraizamiento pertenecieron a los clones X-64, X-65 y X-49. La especificidad entre clon de aislamiento y cepa de rizobacteria es un rasgo encontrado en estudios de inoculación bacteriana en plantas (Enebak et al., 1998; Mafia et al., 2009). Sin embargo, también se ha observado respuestas diferenciales en cuanto a la especie de planta de la cual se aíslan las rizobacterias y su efecto en el crecimiento de estas (Shishido y Chanway, 1998; Enebak, 2005), lo cual puede deberse principalmente a la naturaleza de los exudados de las raíces que varía de acuerdo al genotipo de la planta (Bais et al., 2006).

\section{CONCLUSIONES}

Rizobacterias aisladas desde varios clones de Eucalyptus incrementaron el enraizamiento y longitud de la raíz en dos clones de E. nitens x E. globulus.

- $\quad$ El incremento en el enraizamiento logrado por las rizobacterias fue mayor en el clon $E$. nitens $\times$ E. globulus X-65. 
Hubo diferencias en el enraizamiento al usar miniestacas de tipo apical y de segundo orden, siendo siempre mayor en las primeras para ambos clones utilizados.

\section{REFERENCIAS}

Adesemoye, A. O, Torbert, H. A. and Kloepper, J. W., 2009. Plant Growth-Promoting Rhizobacteria Allow Reduced Application Rates of Chemical Fertilizers. Microbiology Ecology. 58:921-929.

Assis T., Fett Neto, A. and Couto, A., 2004. Current techniques and prospects for the clonal propagation of hardwoods with emphasis on Eucalyptus. Plantation Forest Biotechnology for the $21^{\text {st }}$ Century. 303-333 ISBN: 81-7736-228-3.

Baldini, E., 1992. Arboricultura General. Madrid. Mundi-Prensa. 379p.

Bais, H. P.; Weir, T. L.; Perry, L. G.; Gilroy, S. and Vivanco, J. M., 2006. The Role of Root Exudates in Rhizosphere Interactions with Plants and Other Organisms. Annu. Rev. Plant Biol.57:233-66.

Bhattacharyya, P. N. and Jha, D. K., 2012. Plant growth-promoting rhizobacteria (PGPR): emergence in agriculture. World J Microbiol Biotechnol. 28:1327-1350.

Benizri, E.; Baudoin, E. and Guckert, A., 2001. Root colonization by inoculated plant growth-promoting rhizobacteria. Biocontrol. Sci. Technol., 11: 557-574.

Bent, E.; Breuil, C.; Enebak, S. and Chanway, C., 2002. Surface colonization of Lodgepole Pine (Pinus contorta var. latifolia [Dougl. Engelm.]) roots by Pseudomonas fluorescens and Paenibacillus polymyxa under gnotobiotic conditions. Plant and Soil. 241: 187-196.

Chanway, C., 1997. Inoculation of Tree Roots with Plant Growth Promoting Soil Bacteria: An Emerging Technology for Reforestation. Forest Science 43 (1).

Compant, S.; Clément, C. and Sessitsch, A., 2010. Plant growth-promoting bacteria in the rhizo and endosphere of plants: Their role, colonization, mechanisms involved and prospects for utilization. Soil Biology \& Biochemistry.42: 669-678.

Díaz, K.; Valiente, C..; Martínez, M.; Castillo, M. and Sanfuentes, E., 2008. Root-promoting rhizobacteria in Eucalyptus globulus cuttings. World J. Microbiol. Biotechnol. 25:867-873.

Eneback, S., 2005. Rhizobacteria Isolated from Loblolly Pine Seedlings Mediate Growth-Promotion of Greenhouse-Grown Loblolly, Slash, and Longleaf Pine Seedlings. Forest Science. 51(6).

Erturk, Y.; Ercisli, S.; Haznedar, A. and Cakmakci, R., 2010. Effects of plant growth promoting rhizobacteria (PGPR) on rooting and root growth of kiwifruit (Actinidia deliciosa) stem cuttings. Biol Res 43: 91-98.

Ferreira, A.; Quecine, M. C.; Teixeira, P.; Oda, S.; Azevedo, J. L. and Araújo. W. L., 2008. Diversity of endophytic bacteria from Eucalyptus species seeds and colonization of seedlings by Pantoea agglomerans. FEMS Microbiol Lett. 287: 8-14.

Gray, E. J. and Smith, D. L., 2005. Intracellular and extracellular PGPR: Commonalities and distinctions in the plant-bacterium signaling processes. Soil Biology \& Biochemistry 37: 395-412.

Hand, P., 1994. Biochemical and molecular markers of cellular competence for adventitious rooting. In Biology of Adventitious Root formation. Basic Life Sciences 62: 111-121.

Higashi. E. A.; Vaz de Arruda Silveira, R. L. e Gonçalves, A. N., 2000. Propagaçion vegetativa de Eucalyptus: princípios basicos e a sua evoluçio no Brasil. Circular Técnica IPEF № 192.

Kevers, C.; Hausman, J. F.; Faivre-Rampant, O.; Evers, D. and Gaspar, T., 1997. Hormonal control of adventitious rooting: progress and questions. . J. Appl. Bot. 71: 71-79

Karthikeyan, A. and Sakthivel, K. M., 2011. Efficacy of Azotobacter chrocoocum in Rooting and Growth of Eucalyptus camaldulensis Stem Cuttings. Research Journal of Microbiology.

Kloepper, J. W.; Lifshitz, R. and Zablotowicz, R. M., 1989. Free-living bacterial inocula for enhancing crop productivity. TIB TECH - February. ( $\mathrm{Vol}, 7)$. 
Mafia, R.; Couto, A.; Ferreira, E. M.; Galafazzi, T. e Siqueira, L., 2005. Crescimento de mudas e produtividade de minijardins clonais de eucalipto tratados com rizobacterias selecionadas. Árvore, Viçosa-MG. 29: 843-851.

Mafia, R.; Couto, A.; Maffia, L. A.; Ferreira, E. M. and Siqueira, L., 2007a. Effect of rhizobacteria on rooting and growth of Eucalyptus clones under different conditions of clonal propagation. R. Árvore, Viçosa-MG. 31(5): 813-82.

Mafia, R.; Couto, A.; Ferreira, E. M., Teixeira, D. and Valverde, E. A., 2007b. Rooting induction and growth of eucalyptus by rhizobacteria: effect of addition of nutrient source and growing substrate composition. R. Árvore, Viçosa-MG. 31(4): 589-597.

Mafia, R.; Couto, A.; Maffia, L. A.; Ferreira, E. M.; Breda, D. H. and Siqueira, L., 2009. Microbiolization and interaction between growth promoting rhizobacteria and Eucalyptus clones. R. Árvore, Viçosa-MG. 33(5): 789797.

Pardos, J., 2007. Perspectiva Fisiología en la Producción de y Mejora de Eucalipto (con énfasis en Eucalyptus globulus Labill) Boletín del CIDEU. 3: 7-55.

Penchel, R. M.; Neves, D. C.; Campinhos, C. N.; Evangelista, A. L., e Deschamps, C., 1995. Otimização de parámetros fisiológicos da propagação vegetativa por estaquia de matrizes elite de eucaliptos. In: Congreso Brasileiro De Fisiología vegetal.

Penrose, D. M. and Glick, B. R., 2003. Methods for isolating and characterizing ACC deaminase-containing plant growth-promoting rhizobacteria. Physiologia Plantarum, 118: 10-15.

Ping, L. and Boland, W., 2004. Signals from the undergroup: bacterial volatiles promote growth in Arabidopsis. Trends in Plant Science. 9 (6): 263-266.

Poke, F. S.; Vaillancourt, R. E.; Potts, B. M. and Reid, J. B., 2005. Genomic research in Eucalyptus. Genética. 125:79-101.

Probanza A.; Lucas García, J. A.; Ruiz Palomino, M. R.; Ramos, B. and Gutiérrez, F. J., 2002. Pinus pinea L. seedling growth and bacterial rhizosphere structure after inoculation with PGPR Bacillus (B. licheniformis CECT 5106 and B. pumilus CECT 5105). Applied Soil Ecology. 20: 75-84.

Puente, M. I.; García, J. E.; Pathauer, P. and Perticari, A., 2010. Inoculation with Azospirillum brasilense is a useful tool in Eucalyptus globulus management. American. Eurasian J. Agric. \& Environ Sci. 8(2): 124-130.

Romeiro R. S.; Lanna Filho, R.; Vieira, R.; Alves Silva, H. S. and baracat Pereira, M. C., 2005. Macromolecules released by a plant growth-promoting rhizobacterium as elicitors of systemic resistance in tomato to bacterial and fungal pathogens. Journal Phytopathology. 153: 120-123.

Sasse, J. and Sands, R., 1995. Root system development in cuttings of Eucalyptus globulus. En: B.M. Potts (managing editor), Eucalypt Plantations: Improving, Fibre Yield and Quality. CRCTHF-IUFRO. 299-303.

Schwambach, J.; Fadanelli, C. Fett-Neto, A., 2005. Mineral nutrition and adventitious rooting in microcuttings of Eucalyptus globulus. Tree Physiology. 25: 487-494.

Siddiqui, Z. A., 2006. PGPR: Biocontrol and Biofertilization, Department of Botany, Aligarh Muslim University. Z. A. Siddiqui (ed.) PGPR: prospective biocontrol agents of plant pathogens pp 111-142.

Shishido, M. and Chanway, C., 1998. Forest soil community responses to plant growth-promoting rhizobacteria and spruce seedlings. Biol Fertil Soils 26:178-179.

Sotelo, M. and Monza, J., 2007. Micropropagation of Eucalyptus maidenii elite trees. Agrociencia.11: $81-89$.

Taiz, L., 2007. Fisiología Vegetal. Universitat Jaume I. 672 p.

Teixeira, D.; Couto, A.; Mafia, R.; Ferreira, E. M.; de Siqueira, L.; Maffia, L. A. and Mounteer, H., 2007. Rhizobacterial promotion of Eucalypt rooting and growth. Brazilian Journal of Microbiology. 38:118-123.

Vessey, J., 2003. Plant growth promoting rhizobacteria as biofertilizers. Plant and Soil 255: 571-586.

Xavier, A.; Comério, J. and lannelli, C. M., 1997. Eficiência da microestaquia e da micropropagação na clonagem de Eucalyptus spp. In: lufro Conference on Silviculture and Improvement of Eucalypts, Salvador. Proceedings. Colombo: Embrapa Florestas 4: 40-45. 